\title{
Perinatal and Neonatal Outcome in Multiple Gestations
}

\author{
Jeevan S Nair ${ }^{1}$ \\ ${ }^{1}$ Assistant Professor, Department of Paediatrics, Mount Zion Medical College, Chayalode, Ezhamkulam, Adoor.
}

\section{Abstract}

Background: Fetal growth is independent of the number of fetuses until approximately 30 weeks' gestation, after which growth of multiple gradually falls of compared with singletons. IUGR is defined as an estimated fetal weight (EFW) less than third percentile for gestational age or an $\mathrm{EFW}<10$ th percentile for gestational age in addition to evidence of fetal compromise. The mechanisms are likely uterine crowding, limitation of placental perfusion, and anomalous umbilical cord insertion. Monochrrionic twins are more likely to the IUGR compared with dichorionic twins and have higher perinatal mortality. Neonatal mortality was more in vaginal delivery $90 \%$ that may be due to the increased preterm and low birth weight in this group. Natal complications were more in vaginal delivery. Out of the variables studied, significant influence on neonatal mortality was seen only with discordant twins. Subjects and Methods: This study was carried out among multiple gestation pregnant ladies got admitted at a tertiary care hospital. This was a prospective study. Results: Neonatal mortality was more in vaginal delivery $90 \%$ that may be due to the increased preterm and low birth weight in this group. Natal complications were more in vaginal delivery. Conclusion: Out of the variables studied, significant influence on neonatal mortality was seen only with discordant twins.

Keywords: Fetal growth, Neonatal mortality, Natal complications.

Corresponding Author: Dr. Jeevan S Nair, Assistant Professor, Department of Paediatrics, Mount Zion Medical College, Chayalode, Ezhamkulam, Adoor.

Received: January 2019

Accepted: January 2019

\section{Introduction}

Gestational diabetes has been shown in some studies to be more common in twin pregnancies.

Spontaneous abortion occurs in $8 \%$ to $36 \%$ of multiples pregnancies with reduction to a singleton pregnancy by the end of the first trimester ("vanishing twin"). Possible causes include abnormal implantation, early cardiovascular developmental defects, and chromosomal abnormalities. Before fetal viability, the management of the surviving co twin in a dichorionic pregnancy includes expectant management until term or close to term, in addition to close surveillance for preterm labor, fetal well-being, and fetal growth, The management of a single fetal demise in a monochorionic twin pregnancy is more complicated. The surviving cotwin is at high risk for ischemic multi organ and neurological injury that is thought to be secondary to hypotension or thromboembolic events. Fetal imaging by ultrasonography or magnetic resonance imaging (MRI) may be useful in detecting neurological injury. Termination of pregnancy may be offered as an option when single fetal demise occurs in a prevailed monochorionic twin pregnancy. ${ }^{[1]}$

Incompetent cervix occurs in up to $14 \%$ of multiple gestations. Placental abruption risk rises as the number if fetuses per pregnancy increases. In a large retrospective cohort study, the incidence of placental abruption was 6.2 , 12.2 , and 15.6 per 1,000 pregnancies in singletons, twins, and triplets, respectively.

Preterm premature rupture membrane complicates $7 \%$ to $10 \%$ of twin pregnancies compared with $2 \%$ to $4 \%$ of singleton pregnancies. Preterm labor and birth occur in approximately $57 \%$ twin pregnancies and in $76 \%$ to $90 \%$ of higher-order multiple gestations.

Pregnancy-induced hypertensions (PIH) and preeclampsia are 2.5 times more common in multi fetal pregnancies compared with singleton pregnancies. ${ }^{[2]}$

Approximately $66 \%$ of patients with twins and $91 \%$ of patients with triplets have cesarean delivery. Breech positions of one or more fetuses, cord prolapsed, and placenta! Abruption are factor that account for the increased frequency of cesarean deliveries for twin and multiple gestations. $^{[3]}$

The average duration of gestation is shorter in multi fetal pregnancies, and further shortens as the number of fetuses increased. The mean gestational age at birth is 36,33, and 29 $1 / 2$ weeks, respectively, for twins, triplets, and quadruplets. In developed countries, the incidence of preterm birth in twins was $53 \%$ in 1997 , compared with $9 \%$ to $10 \%$ in singletons. Although most of this increased incidence is due to mild prematurity, multi fetal pregnancy increases the risk of severe prematurity and very low birth weight (VLBW). The likelihood of a birth weight $<1,500 \mathrm{~g}$ is 8 and 33 times 
greater in twins and triplets or higher-order multiples, respectively, compared with singletons. In two multicenter surveys, multiples occurred in $21 \%$ to $24 \%$ of births $<1,500$ $\mathrm{g}$ and in $30 \%$ of births $<1,500 \mathrm{~g}$ and in $30 \%$ of births $<1,000$ g. ${ }^{[4]}$

Fetal growth is independent of the number of fetuses until approximately 30 weeks' gestation, after which growth of multiple gradually falls of compared with singletons (see Fig 7.2). IUGR is defined as an estimated fetal weight (EFW) less than third percentile for gestational age or an EFW $<10$ th percentile for gestational age in addition to evidence of fetal compromise. The mechanisms are likely uterine crowding, limitation of placental perfusion, and anomalous umbilical cord insertion. Monochrrionic twins are more likely to the IUGR compared with dichorionic twins and have higher perinatal mortality. Neonatal morbidities that are seen in $50 \%$ of neonates with IUGR that complicate management of these infants include hypoglycemia, polycythemia, and pulmonary hemorrhage..$^{[5,6]}$

Percentage of the larger twin's weight and can be mild $(<15 \%)$ moderate $(15 \%-30 \%$, or severe $(>30 \%)$. Risk factor for discordant growth include monochorionic Placentation associated with valamentous cord insertion, placental dysfunction, or eclampsia, antepartum bleeding, twin-to twin transfusion syndrome (TTTS), fetal infection, and fetal structural and chromosomal abnormalities. The smaller twin has an increased risk of fetal demise, perinatal death, and preterm birth. Five percent to $15 \%$ of twins and $30 \%$ of triplets will have fetal growth discordance that is associated with a six fold increase in perinatal morbidity and mortality. ${ }^{[7]}$

Intrauterine fetal demise (IUFD) refers to fetal demise after 20 weeks' gestation but before delivery and can be confirmed by ultrasonography evidence of absent fetal cardiac activity. The death of one twin, which occurs in $9 \%$ of multiple pregnancies, is less common in the second and third trimesters. The risk of IUFD is 5 to 6 times greater in $M Z$ pregnancies. Since almost all MZ twins have placental vascular connections with resulting shared circulation, there is a significant risk (20\%-40\%) of neurological injury (multicystic encephalomalacia) to the surviving co twin as a result of associated severe hypotension or thromobo embolic events upon death of the cotwin. Owing to the lack of a shared circulation, the death of one DZ twin usually has minimal adverse effect on the surviving cotwin. In this case, the $\mathrm{c}$ otwin is either completely resorbed if death occurs in the first trimester or is compressed between the amniotic sac of its co twin an the uterine wall (fetus papyraceous). Other complications involving the surviving co twin include antepartum stillbirth, preterm birth, placental abruption, and chorioamnionitis. In the event of a demise of one monocliprionic twin, immediate delivery of the surviving co twin should be considered after fetal viability. However, this does not seem to change the outcome as ncurologic injury is thought to occur at the time of death of the co twin. Disseminated intravascular coagulopathy is a complication seen in $20 \%$ to $25 \%$ of women who retain a dead fetus for $>3$ weeks. ${ }^{[8]}$

\section{Subjects and Methods}

All mothers with multiple gestation considered to this study

- History of any drug intake or assisted reproductive techniques are also taken

- Findings in USG are followed up.

- Cord blood for hemoglobin PVC and blood grouping are sent.

- After delivery placenta is examined to know about chrorinicity.

- Immediate outcome is assessed in neonates such as

- Birth weight

- Chromosomal anomalies

- Deformations

\section{Inclusion criteria}

All multiple deliveries in Hospital $\backslash$

\section{Exclusion Criteria}

Twins and Triplets in OBG ie. new borns brought from other hospitals.

\section{Results}

Table 1: Percentage Distribution of the Sample According to

IUD

\begin{tabular}{|l|l|l|}
\hline IDU & Count & Percentage \\
\hline Yes & 6 & 3.7 \\
\hline No & 157 & 96.3 \\
\hline
\end{tabular}

Table 2: Percentage Distribution of the Sample According to Type of Delivery

\begin{tabular}{|l|l|l|}
\hline Type of delivery & Count & Percentage \\
\hline NVD & 55 & 68.8 \\
\hline LSCS & 19 & 23.8 \\
\hline Forceps & 6 & 7.5 \\
\hline
\end{tabular}

Table 3: Percentage Distribution of the Sample According to Gestational Maturity

\begin{tabular}{|l|l|l|}
\hline Maturation & Count & Percentage \\
\hline Yes & 10 & 12.5 \\
\hline No & 70 & 87.5 \\
\hline
\end{tabular}

Table 4: Percentage Distribution of the Sample According to Major and Minor Anomalies

\begin{tabular}{|l|l|l|}
\hline Anomalies & Count & Percentage \\
\hline Yes & 2 & 1.2 \\
\hline No & 161 & 98.8 \\
\hline
\end{tabular}

Table 5: Percentage Distribution of the Sample According To TTS

\begin{tabular}{|l|l|l|}
\hline TTS & Count & Percentage \\
\hline Yes & 2 & 2.5 \\
\hline No & 78 & 97.5 \\
\hline
\end{tabular}


Nair; Perinatal and Neanatal Outcame in Multiple Gestatians

Table 6: Percentage Distribution of the Sample According to
NICU Admission
\begin{tabular}{|l|l|l|}
\hline NICU & Count & Percentage \\
\hline Yes & 55 & 33.7 \\
\hline No & 108 & 66.3 \\
\hline
\end{tabular}

Table 7: Percentage Distribution of the Sample According to Weight

\begin{tabular}{|l|l|l|}
\hline Weight & Count & Percentage \\
\hline AGA & 72 & 44.2 \\
\hline SGA & 91 & 55.8 \\
\hline
\end{tabular}

Table 8: Percentage Distributio of the Sample According to Discordance

\begin{tabular}{|l|l|l|}
\hline Discordance & Count & Percentage \\
\hline Yes & 29 & 36.3 \\
\hline No & 51 & 63.8 \\
\hline
\end{tabular}

\begin{tabular}{|c|c|c|c|c|c|c|}
\hline \multicolumn{7}{|c|}{ Table 9: Distribution of NM Based on Placenta } \\
\hline \multirow{3}{*}{ Placenta } & \multicolumn{4}{|c|}{ Neonatal mortality } & \multirow{3}{*}{$\mathbf{X} 2$} & \multirow{3}{*}{$\mathbf{P}$} \\
\hline & \multicolumn{2}{|l|}{ No } & \multicolumn{2}{|l|}{ Yes } & & \\
\hline & $\begin{array}{l}\text { Coun } \\
t\end{array}$ & $\begin{array}{l}\text { Percen } \\
t\end{array}$ & Coun & $\begin{array}{l}\text { Percen } \\
t\end{array}$ & & \\
\hline $\begin{array}{l}\text { Monochorioni } \\
\mathrm{c}\end{array}$ & 7 & $14 \%$ & 5 & $16.6 \%$ & $\begin{array}{l}1.3 \\
1\end{array}$ & $\begin{array}{l}\mathrm{P}>0.0 \\
5\end{array}$ \\
\hline Dichorionic & 43 & $86 \%$ & 25 & $83.4 \%$ & & \\
\hline
\end{tabular}

Table 10: Distribution of NM Based on Number of Fetus

\begin{tabular}{|c|c|c|c|c|c|c|}
\hline \multirow{3}{*}{$\begin{array}{l}\text { No.of } \\
\text { Fetus }\end{array}$} & \multicolumn{4}{|c|}{ Neonatal mortality } & \multirow{3}{*}{$\mathrm{X} 2$} & \multirow{3}{*}{$\mathbf{P}$} \\
\hline & \multicolumn{2}{|l|}{ No } & \multicolumn{2}{|l|}{ Yes } & & \\
\hline & Count & Percent & Count & Percent & & \\
\hline Twins & 49 & 98.0 & 28 & 93.3 & & \\
\hline Triplets & 1 & 2.0 & 2 & 6.7 & 1.13 & $\mathrm{P}>0.05$ \\
\hline
\end{tabular}

Table 11: Distribution of NM Based on Types of Delivery

\begin{tabular}{|l|l|l|l|l|l|l|}
\hline \multirow{2}{*}{$\begin{array}{l}\text { Type of } \\
\text { Delivery }\end{array}$} & \multicolumn{3}{|l|}{ Neonatal mortality } & \multirow{2}{*}{ X2 } & \multirow{2}{*}{ Pes } \\
\cline { 2 - 5 } & No & \multicolumn{3}{|l|}{} & \\
\cline { 2 - 5 } & Count & Percent & Count & Percent & & \\
\hline VD & 28 & 56.0 & 27 & 90.0 & & \multirow{2}{*}{10.16} \\
\hline LSCS & 17 & 34.0 & 2 & 6.7 & \\
\hline Forceps & 5 & 10.0 & 1 & 3.3 & & \\
\hline
\end{tabular}

Table 12: Distribution of NM Based on NICU Admission

\begin{tabular}{|l|l|l|l|l|l|l|}
\hline \multirow{2}{*}{$\begin{array}{l}\text { NICU } \\
\text { Admission }\end{array}$} & \multicolumn{3}{|l|}{ Neonatal mortality } & \multirow{2}{*}{ X2 } & \multirow{2}{*}{ P } \\
\cline { 2 - 5 } & No & \multicolumn{3}{|l|}{ Yes } & & \\
\cline { 2 - 5 } & Count & Percent & Count & Percent & & \\
\hline Yes & 37 & 74.0 & 29 & 96.7 & 6.67 & $\mathrm{P}>0.01$ \\
\hline No & 13 & 26.0 & 1 & 3.3 & & \\
\hline
\end{tabular}

Table 13: Distribution of NM Based on NM Based on TTS

\begin{tabular}{|l|l|l|l|l|l|l|}
\hline \multirow{2}{*}{ TTS } & \multicolumn{3}{|l|}{ Neonatal mortality } & \multirow{2}{*}{ X2 } & \multirow{2}{*}{ P } \\
\cline { 2 - 5 } & No & & \multicolumn{2}{|l|}{ Yes } & & \\
\cline { 2 - 5 } & Count & Percent & Count & Percent & & \\
\hline Yes & 1 & 2.0 & 1 & 3.3 & & \\
\hline No & 49 & 98.0 & 29 & 96.7 & 0.14 & \multirow{P}{*}{$>0.05$} \\
\hline
\end{tabular}

\begin{tabular}{|c|c|c|c|c|c|c|}
\hline \multicolumn{7}{|c|}{ Table 14: Distribution of NM Based on Discordance } \\
\hline \multirow{3}{*}{$\begin{array}{l}\text { Discordanc } \\
\text { e }\end{array}$} & \multicolumn{4}{|c|}{ Neonatal mortality } & \multirow{3}{*}{$\mathrm{X} 2$} & \multirow{3}{*}{$\mathbf{P}$} \\
\hline & \multicolumn{2}{|l|}{ No } & \multicolumn{2}{|l|}{ Yes } & & \\
\hline & $\begin{array}{l}\text { Coun } \\
t\end{array}$ & $\begin{array}{l}\text { Percen } \\
t\end{array}$ & $\begin{array}{l}\text { Coun } \\
t\end{array}$ & $\begin{array}{l}\text { Percen } \\
t\end{array}$ & & \\
\hline No & 40 & 80.0 & 11 & 36.7 & & \\
\hline Yes & 10 & 20.0 & 19 & 63.3 & $\begin{array}{l}15.2 \\
4\end{array}$ & $\begin{array}{l}\mathrm{P}>0.0 \\
1\end{array}$ \\
\hline
\end{tabular}

- In this study neonatal mortality was more in dichorionic gestation, most of the deliveries was dichorionic and most of them were preterms. That may be the cause for increased mortality in the same.

- Most common type of delivery was vaginal delivery (68\%) followed by LSCS (23\%).

- Neonatal mortality was more in vaginal delivery $90 \%$ that may be due to the increased preterm and low birth weight in this group. Natal complications were more in vaginal delivery.

- Out of the variables studied, significant influence on neonatal mortality was seen only with discordant twins.

\section{Discussion}

Rates of neonatal mortality are gestational age specific and are similar for singletons, twins, and triplets. Prematurity and low birth weight are the predominating factors that increase the rate of mortality and morbidity for multiple births. Assisted reproduction has contributed to the increased incidence of mlutifetal pregnancies and preterm birth is strongly correlated with the number of fetuses. Therefore, techniques that limit the number of implanted eggs or transferred embryos, or selective reduction of higher-order multiples may improve the likelihood of a successful outcome.

Morbidity Prematurity and growth restriction are associated with an increased risk of morbidities such as bronchopulmonary dysplasia, necrotizing enterocolitis, retinopathy of prematurity, and intraventricular hemorrhage. ${ }^{[9]}$

Long-term morbidity such as CP and other neurological handicaps affects more twins and multiple than singletons. There is a5 - to 10 fold increased risk of CP in multiples compared with singleton gestation. Twins account for $5 \%$ to $10 \%$ of all cases of CP in the United States. The prevalence of $\mathrm{CP}$ in twins is $7.4 \%$, compared with $1 \%$ in singletons. This is related to a number of factors including increased risk of prematurity an low birth weight in multiple births and high risk for cerebral in twins with monochorionic Placentation and in those with TT. ${ }^{[10]}$

Hospital stays for mothers and babies are typically longer for multiple gestations. One study showed that, compared with singletons, average hospital costs were estimated to be 3 and 6 times higher for twins and triplets, respectively; total family costs were 4 and 11 times higher, respectively. The 
increase in multiple births due to the use of assisted reproductive technologies has made an impact on overall medical costs. Thirty-five precent of twins and $75 \%$ of triplets resulted from assisted reproduction techniques. In another study, medical costs from induction of IVF pregnancy until the end of the neonatal period for a twin pregnancy were found to be more than 5 times higher than in a singleton pregnancy. ${ }^{[1]}$

Caring for twins or higher-order multiples contributes to increased marital strain, financial stress, parental anxiety, and depression, and has a greater influence on the professional and social life of mothers of these infants, particularly first-time mother, compared with mother of singletons. In one study, IVF twin parents were found to have a lower risk $(7.3 \%)$ of divorce. Separation compared with parents of control twins (13.3\%) suggesting that IVF twin parents were able to better cope with the increased stress of twins. ${ }^{[12]}$ Multiples are more likely to have medical complications (i.e., prematurity, congential defects, IUGR) that result in prolonged hospital stays that contribute further to a family's emotional and financial stress. Social services, lactation support, and assistance from additional caregivers and family members can help parents cope with the increased amount of care required by multiples. Organization of parents of multiples can provide advice and emotional that can further help new parents of multiples cope.

\section{Conclusion}

- Dichorionic twins accounted for $85 \%$ of twins.

- Preterm deliveries constituted $87.5 \%$ of all deliveries.
- Discordance was present in $56.8 \%$ of all deliveries out of which $65.5 \%$ had neonatal mortality.

- Assisted reproductive techniques were used by $12.5 \%$ of couples.

- TTS was found I 2 gestations out of which one baby required transfusions.

\section{References}

1. Garel M, Blondel B. Assessment at 1 year of the psychological consequences of having triplets. Hum Repred. 1992;7:729-732.

2. Feldman R, Eidelman AI. Parent-infant synchrony and the socialemotional development of triplets. Dev. Psychol. 204;40:1133-1147.

3. Bayley N. Bayley Scales of Infant Development : Administering ad Scoring Mannual. 2nd ed. New York, NY: The Psychological Corp; 1993

4. Feldman R. Mother-Newborn Coding Mannual. Ramat Gan. Israel:Bar IIan University; 1998.

5. Johnston C, Mash EJ. A measure of parenting satisfaction and efficacy.J.Clin Child psychol. 189;18:167-175.

6. Cohen J. A power primer. Psychol Bull. 192;112:155-159.

7. Blickstein I, Kalish RB, Birthweight discordance in multiple pregnancy. Twin Res. 2003;6:526-531.

8. Cleary-Goldman J, D'Altn ME, Berkowitz RL. Prenatal diagnosis and multiple pregnancy. Semin Perinatol 2005;29:312-320

9. Cordero I, Fraco A, Joy SD. Monochorionic monoamiotic twins: Neonatal Outcome. J Perinatol 2006;26:170-175.

10. Garite TJ, Clark RH, Ellott JP, et al. Twins and triplets: The effect of plurality and growth on neonatal Outcome compared with singleton infants. Am J Obstet Gyecol 2004;191:700-707.

11. Moise KJ Jr, Dorman K, Lamvu G, et al. A randomized trial of amnioreduction versus septostomy in the treatment of twin-twin transfusion syndrome. Am J Obstet Gnecol 2005;193: 701-707.

12. Senat MV, Deprest J, Boulvain $M$ et al. Endoscopic laser surgery versus serial amnioreduction for severe twin-to-twin transfusion syndrome. N Engl J Med 2004;351:136-144

Copyright: (C) the author(s), publisher. Asian Journal of Clinical Pediatrics and Neonatology is an Official Publication of "Society for Health Care \& Research Development". It is an open-access article distributed under the terms of the Creative Commons Attribution NonCommercial License, which permits unrestricted non-commercial use, distribution, and reproduction in any medium, provided the original work is properly cited.

How to cite this article: Nair JS. Perinatal and Neonatal Outcome in Multiple Gestations. Asian J. Clin. Pediatr. Neonatol.2018;6(4):9-12. DOI: dx.doi.org/10.21276/ajcpn.2018.6.4.3

Source of Support: Nil, Conflict of Interest: None declared. 